\title{
Do changes in income, deprivation, labour force status and family status influence smoking behaviour over the short run? Panel study of 15 000 adults
}

\section{Citation}

Blakely, Tony, Frederieke S van der Deen, Alistair Woodward, Ichiro Kawachi, and Kristie Carter. 2013. "Do Changes in Income, Deprivation, Labour Force Status and Family Status Influence Smoking Behaviour over the Short Run? Panel Study of 15000 Adults." Tobacco Control 23 (e2): e106-13. https://doi.org/10.1136/tobaccocontrol-2012-050944.

\section{Permanent link}

http://nrs.harvard.edu/urn-3:HUL.InstRepos:41288316

\section{Terms of Use}

This article was downloaded from Harvard University's DASH repository, WARNING: This file should NOT have been available for downloading from Harvard University's DASH repository.

\section{Share Your Story}

The Harvard community has made this article openly available.

Please share how this access benefits you. Submit a story.

\section{Accessibility}




\title{
Do changes in income, deprivation, labour force status and family status influence smoking behaviour over the short run? Panel study of 15000 adults
}

\author{
Tony Blakely, ${ }^{1}$ Frederieke S van der Deen, ${ }^{1}$ Alistair Woodward, ${ }^{2}$ Ichiro Kawachi, ${ }^{3}$ \\ Kristie Carter, ${ }^{1}$ Re-revised and resubmitted to Tobacco Control 10 June 2013
}

'Department of Public Health, University of Otago, Wellington, New Zealand

${ }^{2}$ Faculty of Medical and Health Sciences, School of Population Health, University of Auckland, Auckland, New Zealand ${ }^{3}$ Department of Society, Human Development, and Health, Harvard School of Population Health, Boston, Massachusetts, USA

\section{Correspondence to} Professor Tony Blakely, Department of Public Health, University of Otago, Wellington, PO Box 7343, Wellington 6021,

New Zealand;

tony.blakely@otago.ac.nz

Received 19 December 2012 Accepted 14 August 2013

To cite: Blakely T, van der Deen FS, Woodward A, et al. Tob Control Published Online First: [please include Day Month Year]

doi:10.1136/tobaccocontrol2012-050944

\begin{abstract}
Background Improving social circumstances (eg, an increase in income, finding a job or moving into a good neighbourhood) may reduce tobacco use, but robust evidence on the effects of such improvements is scarce. Accordingly we investigated the link between changing social circumstances and changing tobacco smoking using repeated measures data.
\end{abstract}

Methods 15000 adults with at least two observations over three waves (each 2 years apart) of a panel study had data on smoking status, family, labour force, income and deprivation (both neighbourhood and individual). Fixed effects regression modelling was used.

Findings The odds of smoking increased 1.42-fold (95\% Cl 1.16 to 1.74) for a one log-unit increase in personal income among 15-24-year-olds, but there was no association of increased smoking with an increase in income among 25+ year olds. Moving out of a family nucleus, increasing neighbourhood deprivation (eg, 1.83fold $(95 \% \mathrm{Cl} 1.18$ to 2.83$)$ increased odds of smoking for moving from least to most deprived quintile of neighbourhoods), increasing personal deprivation and moving into employment were all associated with increased odds of smoking. The number of cigarettes smoked a day changed little with changing social circumstances.

Interpretation Worsening social circumstances over the short run are generally associated with higher smoking risk. However, there were counterexamples: for instance, decreasing personal income among young people was associated with decreased odds of smoking, a finding consistent with income elasticity of demand (the less one's income, the less one can consume). This paper suggests that improving social circumstances is not always pro-health over the short run; a more nuanced approach to the social determinants of health is required.

\section{INTRODUCTION}

Social position determines health status. ${ }^{1}$ In most rich countries, lower socioeconomic position is associated with worse health status and a 'poorer' risk factor profile. For example, smoking is more common among low-income groups and deprived populations in New Zealand. ${ }^{2}{ }^{3} \mathrm{~A}$ standard or generalised social determinants perspective ${ }^{1}$ might suggest that improving peoples' education, income and other socioeconomic resources will result in improved health, including, presumably, through pathways such as quitting smoking. For example, according to Lawlor et $a l^{4}$ : "Persistent smoking among the most deprived members of society may represent a rational response to their life chances.... Health promotion initiatives designed to reduce smoking among members of these groups may continue to fail unless the general health and life chances of such individuals are first improved."

However, the connection between social circumstances and smoking is not straightforward. Consider income. A large body of evidence exists that increasing the price of tobacco will reduce consumption and more so among lower socioeconomic groups. ${ }^{5}{ }^{6}$ The corollary of this is that, all other things equal (ceteris paribus), increasing income will be associated with increased smoking as one's disposable income goes up. Indeed, for young adolescents, a positive association has been found between a higher disposable income and smoking. ${ }^{7-9}$ This equates to an 'income elasticity' of demand for tobacco that, presumably, mirrors the price elasticity and, at least in the short term, runs contrary to the notion that health (or in this case, risky behaviour) uniformly improves with improving socioeconomic position. The aim of this paper is therefore to test the short-run causal associations of a change in social circumstances with a change in smoking behaviour.

Causal associations between social determinants and health can be thought of over the short run and long run, and they may be in opposite directions. For example, a short-term increase in income may be associated with a temporary increase in consumption of 'bad' behaviours (eg, smoking more, eating too much and drinking too much). However, if the increase in income is sustained over a longer time horizon, this may change the incentives faced by the individual. In other words, the expectation of a more comfortable existence stretching into the future may increase the marginal utility of investing in health and longevity (ie, by stopping smoking)..$^{10} 11$

Generating robust evidence free of confounding on either the short-run or (especially) long-run causation is difficult. Randomised trials are difficult to conduct. Therefore, we have to rely on other study designs. One such study design for testing short-run associations is a panel study or repeated measures. ${ }^{12}{ }^{13}$ As the same individuals are repeatedly assessed over time, it is assumed that all timeinvariant covariates (eg, intelligence, early childhood exposures, personality, etc.) are controlled, 
and one can make stronger causal inference interpretations about any change in outcome (in this study, smoking behaviour) associated with change in exposure (in this study, social position determinants: family status, labour force status, income and deprivation).

There is surprisingly little published evidence using such a panel study design wherein both a change in social exposure and a change in health outcome are studied. The studies that have researched the temporal relation between a change in social determinants and a change in smoking behaviour have generally focused on change in marital status, suggesting marital dissolution increases the risk of smoking in both men and women. ${ }^{14-18}$ The association between changes in employment status, income and deprivation and smoking patterns is less clear. For example, while Virtanen et $a l^{19}$ found employment trajectory to be (variably) associated with alcohol consumption, body weight, physical activity and sleep duration, it was not significantly associated with smoking. Stable employment has been linked with moving from smoking into non-smoking, although the same study found no association of changes in individual or household income with changes in smoking behaviour. ${ }^{17}$ Increasing exposure to financial strain (a similar measure to deprivation) has been demonstrated to be associated with a higher likelihood of smoking, particularly among the young-old generation (65-74 years old). ${ }^{20}$ But overall evidence on the association between changes in employment status, income and deprivation on changes in smoking seems to be scarce.

In the present study, we examine the association of changing social circumstances (family status, labour force status, income and deprivation) with two aspects of smoking behaviour in a panel study of 15000 adults (aged 15+), namely, (1) smoking: yes (current) or no (ex-smoker or never-smoker); and (2) number of cigarettes smoked per day. We used fixed effects analyses that remove all observable and unobservable timeinvariant confounding, allowing a more robust assessment of causal associations than is possible with non-repeated measures data-at least over the short run.

\section{METHODS}

Data

This study is a longitudinal analysis of waves 3, 5 and 7 from the Survey of Families, Income and Employment (SoFIE). This nationally representative longitudinal survey of the usually resident population living in private households was conducted from 2002 to 2010 in New Zealand. ${ }^{21}$ Information on individual and family factors such as labour force status, education, marital status and income was obtained during annual face-to-face interviews. In waves 3, 5 and 7 of SoFIE, a detailed health module included smoking questions. The initial SoFIE sample comprised approximately 11500 responding private households (response rate of $77 \%$ at wave 1). Over 22000 adults responded in wave 1 and just over 16000 in wave 7 . In this paper, eligible respondents were those aged $15+$ years who responded to all of waves 3,5 and 7 , plus those responding to just waves 3 and 5 and just waves 5 and $7(\mathrm{~N}=17$ 140).

\section{Exposure measures}

Income

Annual personal income was derived by adding up gross annual incomes from employment earnings, self-employment earnings, government transfers, interest from bank and/or other accounts, personal investments, private superannuation and pension schemes and other regular or irregular received income sources. We modelled both total household income (equivalised for economies of scale using a New Zealand-specific index) and personal income. Both measures were adjusted for inflation and log-transformed prior to modelling.

\section{Family status}

The family status of a respondent was based on circumstances at the time of the survey and included a couple without child(ren), a couple with child(ren), sole parent with child(ren) or not living in a family nucleus (eg, living alone or in a flatting/house share situation). If a young person, aged 16 , is living at home with his/her parents, he/she will be classified as living in a couple with child(ren) family.

\section{Labour force status}

Respondent's labour force status was classified as employed, unemployed (but actively seeking for a job) or inactive. The latter inactive category is heterogeneous, including those people 'out of work' but not actively seeking work, caregivers (eg, parents), students and the retired.

\section{Neighbourhood deprivation}

A 2006 census-based measure of neighbourhood deprivation, using an index of nine census variables (eg, benefit receipt, income) averaged across about 100 people living in the smallest census enumeration area (ie, meshblock), ${ }^{22}$ was assigned to each respondent and classified as quintiles - and allowed to change if respondents moved between waves. This variable is therefore a relative ranking of neighbourhood deprivation.

\section{Personal deprivation}

An eight-item measure of personal deprivation (eg, not being able to afford fruit and vegetables, using a food bank $)^{23}$ was asked of all respondents at each of waves 3, 5 and 7. The questions address moderate-to-severe personal deprivation, meaning that the measure can be considered akin to an absolute measure of hardship. The majority of people answered 'no' to all eight questions and were classified in the referent 'nil' personal deprivation category. The remaining respondents were classified as 1 to 2 , or $3+$ 'yes' answers with the $3+$ category being the minority of people with severe personal deprivation.

\section{Self-rated health}

Five category answer to the question: "In general would you say your health is: excellent, very good, good, fair or poor?"

\section{Outcome measures}

\section{Smoking status}

Respondent's smoking status was classified as never-smoker, ex-smoker or current smoker based on two questions: "Do you regularly smoke one or more tobacco cigarettes a day?" and "Ever been a regular smoker of one or more cigarettes a day?". For the fixed effects analysis, never-smokers and ex-smokers were grouped together, meaning that predictors of change from not currently to current smoker were modelled.

\section{Number of cigarettes smoked per day}

For current smokers, the number of cigarettes per day was determined by asking: "About how many cigarettes do you usually smoke a day?" Response categories were up to 4 per day, 5-9 per day, ...., 40-44 per day and 45 or more per day. These were coded into midband rates, $2,7, \ldots ., 42$ and 47 , and modelled as a continuous outcome in linear fixed effects regressions. 


\section{Analyses}

All analyses were conducted using individual unit data in Statistical Analysis System (SAS) Enterprise Guide in the Statistics New Zealand data laboratory. Fixed effects regression models were used to estimate the relationship between a change over time in each of the exposure variables and a change in the two outcome variables. For example, for a logistic regression model of the outcome variable smoking/non-smoking, an OR of 1.5 for the natural logarithm of personal income means that someone who increases his/her income by $170 \%(\exp [1]=2.7)$ has a $50 \%$ higher odds of becoming a smoker than someone who has experienced no change in his/her personal income. (Interpreting parameters for categorical variables is more complicated and will be elucidated in the results below using family status.)

We used a sequence of models: (1) family and labour force status (modelled first as considered causally prior to any impact on change in remaining socioeconomic factors); (2) plus household income; (3) as household income is usually not important, we substitute it with personal income; and (4) model 3 plus remaining deprivation variables.

We also split the sample into 15-24-year-olds and 25+ year olds. As most initiation of smoking has occurred by age $25,{ }^{24}$ the fixed effects regression among $25+$ year olds will reflect the net 'flow' of cessation (current to ex) and relapse (ex to current), and among 15-24 years, it will reflect more (but not exclusively) initiation.

\section{RESULTS}

The distribution of smoking at each wave, and transitions between waves, is shown in table 1 .

Among respondents with complete data, 19.2\% were current smokers at wave 3 reducing to $17.0 \%$ at wave 7 , although these cross-sectional prevalences hide many of the between-wave transitions. Around 2\% of respondents either started or stopped smoking between waves-with slightly more stopping, leading to the modest reduction in smoking prevalence over time. The mean number of cigarettes consumed was relatively stable over time at about 13 cigarettes per day. Over half of continuous current smokers changed the number of cigarettes they smoked between waves and were equally split between increasing and decreasing.

The distribution of covariates is similarly shown in table 2 .

Of most importance for the fixed effects analyses are those respondents experiencing change over time. Slightly more than $10 \%$ of respondents experienced a change in labour force status between waves, and up to a third of respondents experienced either a decrease or increase in log income (be it household or personal) of greater than half an SD. About $15 \%$ of respondents experienced some change in family status between waves. A quarter of respondents reported a change in personal deprivation level between waves, and $15 \%$ to $20 \%$ a change in neighbourhood deprivation between waves.

\section{Odds of smoking}

Table 3 shows the results for sequential logistic fixed effects models with smoking status as the outcome variable.

As results change little for sequential addition of covariates, we first focus on model 4 , including all covariates. The results for a categorical independent variable in a fixed effects model for panel data require careful interpretation. Consider the 'not in family nucleus' OR of 1.77 (95\% CI 1.26 to 2.47). This means that someone changing from the referent category of 'couple only' to 'not in family nucleus' has a $77 \%$ greater odds of becoming a smoker than someone not changing his/her family status between waves. And conversely, someone shifting the other way ('not in family nucleus' to 'couple only') has a

Table 1 Distribution and transitions of smoking status for all 15+ year olds ( $n=17$ 140; percentages in parentheses for non-missing respondents and data)

\begin{tabular}{|c|c|c|c|c|c|}
\hline $\begin{array}{l}\text { Smoking variable/ } \\
\text { transition }\end{array}$ & Wave 3 & Wave $3-5$ transition & Wave 5 & Wave 5-7 transition & Wave 7 \\
\hline Smoking status & $\begin{array}{l}(\mathrm{N}=16835 \\
\text { non-missing) }\end{array}$ & ( $\mathrm{N}=16580$ non-missing) & $\begin{array}{l}(\mathrm{N}=16855 \\
\text { non-missing) }\end{array}$ & (N=14 920 non-missing) & $\begin{array}{l}(\mathrm{N}=15100 \\
\text { non-missing) }\end{array}$ \\
\hline Never & $8875(52.7 \%)$ & & $8775(52.1 \%)$ & & 7775 (51.5\%) \\
\hline Ex-smoker & $4735(28.1 \%)$ & & $4920(29.2 \%)$ & & $4760(31.5 \%)$ \\
\hline Current & $3225(19.2 \%)$ & & $3160(18.7 \%)$ & & $2565(17.0 \%)$ \\
\hline Missing smoking data & 310 & & 290 & & 120 \\
\hline Stopped smoking* & & $445(2.4 \%)$ & & $490(2.1 \%)$ & \\
\hline Started smoking & & $380(2.3 \%)$ & & $280(1.9 \%)$ & \\
\hline Stayed smoking & & $2660(16.2 \%)$ & & $2195(15.0 \%)$ & \\
\hline Stayed non-smokingt & & $13110(79.1 \%)$ & & $11955(81.0 \%)$ & \\
\hline Missing $\geq 1$ wave & & 525 & & 180 & \\
\hline $\begin{array}{l}\text { Number of cigarettes } \\
\text { smoked } \neq\end{array}$ & $\begin{array}{l}\text { (N=3225 current } \\
\text { smokers) }\end{array}$ & $\begin{array}{l}\text { ( } \mathrm{N}=2660 \text { smokers in both } \\
\text { waves) }\end{array}$ & $\begin{array}{l}\text { ( } \mathrm{N}=3160 \text { current } \\
\text { smokers) }\end{array}$ & $\begin{array}{l}\text { ( } \mathrm{N}=2195 \text { smokers in both } \\
\text { waves) }\end{array}$ & $\begin{array}{l}\text { ( } \mathrm{N}=2565 \text { current } \\
\text { smokers) }\end{array}$ \\
\hline Mean (SD) & $13.17(7.78)$ & & $13.04(7.79)$ & & $13.46(7.98)$ \\
\hline Increase by $>0.5$ SD & & $765(28.8 \%)$ & & $620(28.2 \%)$ & \\
\hline No change & & $1150(43.2 \%)$ & & $1000(45.5 \%)$ & \\
\hline Decrease by $>0.5$ SD & & $735(27.6 \%)$ & & $565(25.7 \%)$ & \\
\hline
\end{tabular}


Table 2 Distribution of independent covariates data for all 15+ year olds with data at each wave or both waves for transitions ( $n=17$ 140; percentages in parentheses for non-missing respondents and data)

\begin{tabular}{|c|c|c|c|c|c|}
\hline Variable* & Wave 3 & Wave $3-5$ transition & Wave 5 & Wave 5-7 transition & Wave 7 \\
\hline \multicolumn{6}{|l|}{ Labour force status } \\
\hline Working & $11320(66.2 \%)$ & & $11585(67.7 \%)$ & & $10225(67.7 \%)$ \\
\hline Not active & $5485(32.2 \%)$ & & $5260(30.6 \%)$ & & $4630(30.6 \%)$ \\
\hline Unemployed & $290(1.7 \%)$ & & $260(1.7 \%)$ & & $255(1.7 \%)$ \\
\hline Stayed working & & 10335 (60.6\%) & & $9460(62.7 \%)$ & \\
\hline Stayed not working & & $4550(26.7 \%)$ & & $3920(26.0 \%)$ & \\
\hline Working to not working & & $965(5.7 \%)$ & & $960(6.4 \%)$ & \\
\hline Not working to working & & $1215(7.1 \%)$ & & $745(4.9 \%)$ & \\
\hline \multicolumn{6}{|c|}{ Log equiv household income (CPI adjusted) } \\
\hline Mean (SD) & $10.64(0.84)$ & & $10.68(0.82)$ & & $10.71(0.81)$ \\
\hline Increase by $>0.5 \mathrm{SD}$ & & $3075(18.2 \%)$ & & $2410(15.9 \%)$ & \\
\hline No change & & $11315(66.8 \%)$ & & $10355(68.4 \%)$ & \\
\hline Decrease by $>0.5$ SD & & $2550(15.1 \%)$ & & $2370(15.7 \%)$ & \\
\hline \multicolumn{6}{|l|}{ Log personal income (CPI adjusted) } \\
\hline Mean (SD) & $9.75(1.25)$ & & $9.92(1.11)$ & & $10.03(1.05)$ \\
\hline Increase by $>0.5 \mathrm{SD}$ & & $3475(20.3 \%)$ & & $2755(18.6 \%)$ & \\
\hline No change & & $11700(68.3 \%)$ & & $10025(67.6 \%)$ & \\
\hline Decrease by $>0.5$ SD & & $1945(11.4 \%)$ & & $2045(13.8 \%)$ & \\
\hline \multicolumn{6}{|l|}{ Family status } \\
\hline Couple only & $4875(28.5 \%)$ & & $5045(29.5 \%)$ & & $4765(31.5 \%)$ \\
\hline Couple with children & $7035(41.2 \%)$ & & $6570(38.4 \%)$ & & $5785(38.3 \%)$ \\
\hline Sole parent & $1555(9.1 \%)$ & & $1495(8.7 \%)$ & & $1265(8.4 \%)$ \\
\hline Not in a family nucleus & $3320(19.4 \%)$ & & $3700(21.6 \%)$ & & $3445(22.8 \%)$ \\
\hline Couple only both waves & & $4120(25.0 \%)$ & & $3930(26.2 \%)$ & \\
\hline Couple with children both waves & & $5845(35.5 \%)$ & & $5130(34.2 \%)$ & \\
\hline Sole parent both waves & & $1095(6.6 \%)$ & & $945(6.3 \%)$ & \\
\hline Not in a family both waves & & $2700(16.4 \%)$ & & $2585(17.2 \%)$ & \\
\hline Change in family status & & $2715(16.5 \%)$ & & $2405(16.0 \%)$ & \\
\hline \multicolumn{6}{|l|}{ Personal deprivation } \\
\hline Nil (least deprived) & $12075(70.6 \%)$ & & $12445(72.8 \%)$ & & $10455(69.2 \%)$ \\
\hline 1 to 2 & $3390(19.8 \%)$ & & $3290(19.2 \%)$ & & $3615(23.9 \%)$ \\
\hline 3 or more (most deprived) & $1065(6.2 \%)$ & & $895(5.2 \%)$ & & $1015(6.7 \%)$ \\
\hline Increasing deprivation & & $1975(12.3 \%)$ & & $2715(18.5 \%)$ & \\
\hline No change & & $11610(72.2 \%)$ & & $10435(71.1 \%)$ & \\
\hline Decreasing deprivation & & $2490(15.5 \%)$ & & $1530(10.4 \%)$ & \\
\hline \multicolumn{6}{|l|}{ Neighbourhood deprivation } \\
\hline Quintile 1 (least) & $3540(20.7 \%)$ & & $3560(20.8 \%)$ & & $3380(22.4 \%)$ \\
\hline Quintile 2 & $3530(20.6 \%)$ & & $3615(21.1 \%)$ & & $3350(22.2 \%)$ \\
\hline Quintile 3 & $3100(18.1 \%)$ & & $3170(18.5 \%)$ & & $2935(19.4 \%)$ \\
\hline Quintile 4 & $3515(20.6 \%)$ & & $3440(20.1 \%)$ & & $3065(20.3 \%)$ \\
\hline Quintile 5 (most) & $3095(18.1 \%)$ & & $3020(17.7 \%)$ & & $2565(17.0 \%)$ \\
\hline Increase & & $1630(9.9 \%)$ & & $1305(8.7 \%)$ & \\
\hline No change & & $13080(79.4 \%)$ & & $12285(81.7 \%)$ & \\
\hline Decrease & & $1760(10.7 \%)$ & & $1440(9.6 \%)$ & \\
\hline
\end{tabular}

${ }^{*}$ Non-respondents or missing cases on each variable not shown.

$\mathrm{CPI}$, consumer price index;

$44 \%$ lesser odds $(100 \%-100 \% \times 1 / 1.77)$. The interpretations for the two other non-referent categories are similar, and the OR for moving from 'couple only' to 'couple with children' is protective with a $95 \%$ CI just including the null $(0.73,0.53$ to 1.02). Next, given the imposed mathematical structure of the fixed effects model, one can also calculate other transitions of interest, for example, the OR for 'couple with children' to 'not in family nucleus' is $1.77 / 0.73=2.42$. Finally, one can assess the statistical significance of the overall family status variable with the type III $\mathrm{p}$ value, which in this case is highly statistically significant $(p<0.001)$.
Transition between waves from employed to inactive was associated with a $32 \%$ decrease in the odds of smoking $(95 \% \mathrm{CI}$ 12 to 47). The transition from employed to unemployed was associated with a $57 \%$ increase in the odds of smoking, but the 95\% CI included the null (ie, 1.0). It is plausible that timevarying health status is confounding the association of moving into the inactive group with decreasing odds of smoking (eg, those becoming unwell may both move out of active labour force and stop smoking due to poor health). Therefore, we also ran model 4, including self-rated health, but the results barely changed (data not shown). 
Table 3 Fixed effects logistic regression model of smoking status (current vs ex and never combined)

\begin{tabular}{|c|c|c|c|c|c|c|c|c|c|c|c|c|}
\hline \multirow[b]{2}{*}{ Model Variable } & \multicolumn{2}{|c|}{ 1: family and LFS } & \multicolumn{2}{|c|}{$\begin{array}{l}\text { 2: } 1 \text { plus household } \\
\text { income }\end{array}$} & \multicolumn{2}{|c|}{$\begin{array}{l}\text { 3: } 1 \text { plus personal } \\
\text { income }\end{array}$} & \multicolumn{2}{|c|}{$\begin{array}{l}\text { 4: } 3 \text { plus } \\
\text { deprivation }\end{array}$} & \multicolumn{2}{|c|}{$\begin{array}{l}\text { 5a: } 4 \text { restricted to } \\
<25 \text { years* }\end{array}$} & \multicolumn{2}{|c|}{$\begin{array}{l}5 \mathrm{~b}: 4 \text { restricted to } \\
25+\text { years* }\end{array}$} \\
\hline & OR & $95 \% \mathrm{Cl}$ & $\mathrm{OR}$ & $95 \% \mathrm{Cl}$ & OR & $95 \% \mathrm{Cl}$ & OR & $95 \% \mathrm{Cl}$ & OR & $95 \% \mathrm{Cl}$ & OR & $95 \% \mathrm{Cl}$ \\
\hline \multicolumn{13}{|l|}{ Family status } \\
\hline Not in family nucleus & 1.80 & 1.29 to 2.50 & 1.83 & 1.31 to 2.55 & 1.77 & 1.27 to 2.47 & 1.77 & 1.26 to 2.47 & 1.56 & 0.85 to 2.89 & 1.63 & 1.07 to 2.49 \\
\hline Sole parent & 0.98 & 0.64 to 1.49 & 0.98 & 0.64 to 1.50 & 0.99 & 0.65 to 1.51 & 1.03 & 0.68 to 1.58 & 0.79 & 0.39 to 1.62 & 1.58 & 0.90 to 2.80 \\
\hline Couple with children & 0.63 & 0.46 to 0.87 & 0.63 & 0.46 to 0.87 & 0.68 & 0.49 to 0.94 & 0.73 & 0.53 to 1.02 & 0.54 & 0.29 to 1.00 & 1.03 & 0.68 to 1.56 \\
\hline Couple only (ref.) & 1 & & 1 & & 1 & & 1 & & 1 & & 1 & \\
\hline$p$ Valuet & & $<0.001$ & & $<0.001$ & & $<0.001$ & & $<0.001$ & & $<0.001$ & & 0.063 \\
\hline \multicolumn{13}{|l|}{ Labour force status (LFS) } \\
\hline Inactive & 0.60 & 0.47 to 0.76 & 0.60 & 0.47 to 0.77 & 0.70 & 0.54 to 0.90 & 0.68 & 0.53 to 0.88 & 0.93 & 0.60 to 1.45 & 0.67 & 0.48 to 0.94 \\
\hline Unemployed & 1.58 & 0.95 to 2.64 & 1.59 & 0.95 to 2.65 & 1.75 & 1.04 to 2.93 & 1.57 & 0.92 to 2.66 & 1.71 & 0.76 to 3.84 & 1.42 & 0.68 to 2.96 \\
\hline Employed (ref.) & 1 & & 1 & & 1 & & 1 & & 1 & & 1 & \\
\hline $\mathrm{p}$ Valuet & & $<0.001$ & & $<0.001$ & & $<0.001$ & & 0.001 & & 0.353 & & 0.026 \\
\hline $\begin{array}{l}\text { Log household income } \\
\text { p Valuet }\end{array}$ & & & 1.06 & $\begin{array}{l}0.94 \text { to } 1.20 \\
0.314\end{array}$ & & & & & & & & \\
\hline $\begin{array}{l}\text { Log personal income } \\
\text { p Valuet }\end{array}$ & & & & & 1.23 & $\begin{array}{l}1.12 \text { to } 1.36 \\
<0.001\end{array}$ & 1.22 & $\begin{array}{l}1.11 \text { to } 1.35 \\
<0.001\end{array}$ & 1.42 & $\begin{array}{l}1.16 \text { to } 1.74 \\
<0.001\end{array}$ & 0.99 & $\begin{array}{l}0.87 \text { to } 1.11 \\
0.726\end{array}$ \\
\hline \multicolumn{13}{|l|}{ Individual deprivation‡ } \\
\hline Nil & & & & & & & 1 & & 1 & & 1 & \\
\hline 1 to 2 & & & & & & & 1.18 & 0.97 to 1.44 & 1.27 & 0.87 to 1.85 & 1.01 & 0.80 to 1.29 \\
\hline 3 or more & & & & & & & 1.60 & 1.12 to 2.27 & 1.63 & 0.85 to 3.12 & 1.37 & 0.89 to 2.10 \\
\hline $\mathrm{p}$ Valuet & & & & & & & & 0.028 & & 0.276 & & 0.298 \\
\hline \multicolumn{13}{|c|}{ Neighbourhood deprivation§ } \\
\hline Quintile 1 (least) & & & & & & & 1 & & 1 & & 1 & \\
\hline Quintile 2 & & & & & & & 0.96 & 0.64 to 1.45 & 0.92 & 0.46 to 1.84 & 1.06 & 0.63 to 1.81 \\
\hline Quintile 3 & & & & & & & 1.38 & 0.92 to 2.09 & 1.30 & 0.64 to 2.64 & 1.32 & 0.77 to 2.24 \\
\hline Quintile 4 & & & & & & & 1.47 & 0.99 to 2.18 & 1.19 & 0.61 to 2.30 & 1.35 & 0.80 to 2.28 \\
\hline Quintile 5 (most) & & & & & & & 1.83 & 1.18 to 2.83 & 1.31 & 0.64 to 2.66 & 1.80 & 1.00 to 3.25 \\
\hline $\mathrm{p}$ Valuet & & & & & & & & 0.022 & & 0.819 & & 0.341 \\
\hline
\end{tabular}

*In addition to these models run separately for $<25$ and $\geq 25$ year olds, a model was run with all ages combined with interaction terms of age (dichotomous, $<25$ vs $\geq 25$ years) with all time-varying covariates shown in this table. Only the interaction with the logarithm of personal income was statistically significant ( $p<0.001)$. $p$ Values for other interactions were family status 0.12 ; labour force status 0.38 ; individual deprivation 0.31 ; and neighbourhood deprivation 0.94 .

tType III Wald tests, which for multichotomous categorical variables (eg, labour force status) provides a statistical test of the whole construct (not just one non-referent compared with referent comparison).

¥Models were also run with NZiDep as a continuous variable, coded $0.1,2$ for the three levels. The OR $(95 \% \mathrm{Cl})$ by model were $4=1.23(1.05$ to 1.44$) ; 5 a=1.28(0.96$ to 1.73$)$; and $5 b=1.12$ (0.92 to 1.36). Coefficients for other covariates in the model change little.

§Models were also run with NZDep as a continuous variable, coded $0,1,2,3,4$ for the five levels. The OR (95\% CI) by model were $4=1.17(1.06$ to 1.30$) ; 5 a=1.08(0.92$ to 1.27$)$; and $5 b=1.14$ ( 1.00 to 1.31$)$. Coefficients for other covariates in the model change little.

As changes in smoking status up to 25 years of age are largely driven by initiation, and beyond the age of 25 largely by cessation and relapse, we tested for interactions of all time-varying covariates in model 4 with this age dichotomisation (see footnotes to table 3 ) and ran models separately by age (models 5a and $5 \mathrm{~b}$ ). The only statistically significant interaction was with personal income $(\mathrm{p}<0.001)$, whereby a one-unit increase in the log of personal income (a 2.72-fold increase in personal income) was associated with a 1.42 increased odds of smoking among $15-24$-year-olds (95\% CI 1.16 to 1.74 ) but had no association among $25+$ year olds (OR 0.99).

Regarding deprivation, if someone transitioned from nil to high personal deprivation between waves, his/her odds of smoking increased by $60 \%$ compared with someone with no change in deprivation (OR $1.60,95 \%$ CI 1.12 to 2.27 ; model 4 , table 3 ) and the type III p value was 0.028 . Increasing neighbourhood deprivation, from shifting residence, was also strongly associated with increased odds of smoking for all ages combined. For example, moving from quintile 1 to quintile 5 was associated with a 1.83 increased odds of smoking (95\% CI 1.18 to 2.83), and treating deprivation quintile as a continuous variable (given the mostly monotonic and linear association for the categorical specification) a one quintile increase in deprivation was associated with a 1.17 increased odds of smoking (1.06-1.30; footnotes to table 3).

\section{Number of cigarettes per day among smokers}

Table 4 shows the linear regression results for the number of cigarettes smoked per day, restricted to respondents smoking in two adjacent waves.

Strong patterns are not evident. However, there is a strong impact of family status on the number of cigarettes consumed (type III $\mathrm{p}$ value $=0.004$ in the fully adjusted model). There is evidence that transitioning from couple only to becoming a sole parent is associated with an increase of smoking of 0.78 more cigarettes per day (95\% CI -0.01 to 1.57 ) compared with no change in family status. The more conceptually relevant comparison though is moving from a couple with children to sole parent family. After changing the reference group in this analysis only, respondents transitioning from 'couple with children' to 'sole parent' family have an expected increase of 1.21 cigarettes (95\% CI 0.53 to 1.89 ). Increasing personal deprivation was 
Table 4 Fixed effects linear regression model of number of cigarettes smoked per day (among continuing smokers)

\begin{tabular}{|c|c|c|c|c|c|c|c|c|}
\hline \multirow{2}{*}{$\begin{array}{l}\text { Model } \\
\text { Variable }\end{array}$} & \multicolumn{2}{|c|}{ 1: family and LFS } & \multicolumn{2}{|c|}{ 2: 1 plus household income } & \multicolumn{2}{|c|}{ 3: 1 plus personal income } & \multicolumn{2}{|c|}{ 4: 3 plus deprivation } \\
\hline & $\boldsymbol{\beta}$ & $95 \% \mathrm{Cl}$ & $\boldsymbol{\beta}$ & $95 \% \mathrm{Cl}$ & $\boldsymbol{\beta}$ & $95 \% \mathrm{Cl}$ & $\boldsymbol{\beta}$ & $95 \% \mathrm{Cl}$ \\
\hline \multicolumn{9}{|l|}{ Family status } \\
\hline Not in family nucleus & 0.31 & $(-0.32$ to 0.93$)$ & 0.35 & $(-0.28$ to 0.97$)$ & 0.30 & $(-0.32$ to 0.93$)$ & 0.31 & $(-0.31$ to 0.94$)$ \\
\hline Sole parent & 0.75 & $(-0.04$ to 1.53$)$ & 0.69 & $(-0.10$ to 1.48$)$ & 0.74 & $(-0.05$ to 1.53$)$ & 0.78 & $(-0.01$ to 1.57$)$ \\
\hline Couple with children & -0.43 & $(-1.05$ to 0.19$)$ & -0.43 & $(-1.06$ to 0.19$)$ & -0.43 & $(-1.05$ to 0.20$)$ & -0.43 & $(-1.06$ to 0.19$)$ \\
\hline Couple only (ref.) & 0 & & 0 & & 0 & & 0 & \\
\hline p Value* & & 0.005 & & 0.005 & & 0.006 & & 0.004 \\
\hline \multicolumn{9}{|l|}{ Labour force status (LFS) } \\
\hline Inactive & -0.74 & $(-1.21$ to -0.27$)$ & -0.75 & $(-1.22$ to -0.27$)$ & -0.72 & $(-1.20$ to -0.23$)$ & -0.70 & $(-1.18$ to -0.21$)$ \\
\hline Unemployed & -0.58 & $(-1.37$ to 0.22$)$ & -0.60 & $(-1.39$ to 0.20$)$ & -0.56 & $(-1.36$ to 0.24$)$ & -0.46 & $(-1.27$ to 0.35$)$ \\
\hline Employed (ref.) & 0 & & 0 & & 0 & & 0 & \\
\hline p Value* & & 0.008 & & 0.008 & & 0.013 & & 0.018 \\
\hline Log household income & & & 0.04 & $(-0.21$ to 0.29$)$ & & & & \\
\hline p Value* & & & & 0.912 & & & & \\
\hline Log personal income & & & & & 0.04 & $(-0.15$ to 0.23$)$ & 0.04 & $(-0.16$ to 0.23$)$ \\
\hline$p$ Value* & & & & & & 0.703 & & 0.707 \\
\hline \multicolumn{9}{|l|}{ Individual deprivation } \\
\hline Nil & & & & & & & 0 & \\
\hline 1 to 2 & & & & & & & -0.11 & $(-0.47$ to 0.27$)$ \\
\hline 3 or more & & & & & & & -0.42 & $(-1.00$ to 0.17$)$ \\
\hline p Value* & & & & & & & & 0.369 \\
\hline \multicolumn{9}{|c|}{ Neighbourhood deprivation } \\
\hline Quintile 1 (least) & & & & & & & 0 & \\
\hline Quintile 2 & & & & & & & 0.10 & $(-0.74$ to 0.94$)$ \\
\hline Quintile 3 & & & & & & & -0.01 & $(-0.79$ to 0.77$)$ \\
\hline Quintile 4 & & & & & & & 0.11 & $(-0.70$ to 0.92$)$ \\
\hline Quintile 5 (most) & & & & & & & 0.10 & $(-0.75$ to 0.95$)$ \\
\hline p Value* & & & & & & & & 0.995 \\
\hline
\end{tabular}

*Type III Wald tests, which for multichotomous categorical variables (eg, labour force status) provides a statistical test of the whole construct (not just one non-referent compared with referent comparison).

associated with reducing the number of cigarettes per day smoked, but the CI included the null. There was no clear association with increasing neighbourhood deprivation.

\section{DISCUSSION}

In the absence of randomised trials on the association of social circumstances with health, repeated measures data where one can observe whether changes over time in social circumstances are associated with changing health status present a strong study design for causal inference. We find strong associations of changing social circumstances with the odds of smoking, but only modest to moderate associations of changing social circumstances with the number of cigarettes smoked per day among respondents who continue to smoke. Table 5 gives a stylised summary of changes in smoking behaviour for what would be usually considered deterioration in social circumstances.

First, the odds of smoking in response to income varies by age: increasing income increases the odds of smoking among young people (almost certainly through an initiation pathway) but has no detectable effect among older people. Decreasing income seemingly has no effect on the number of cigarettes smoked.

Second, increasing deprivation (both personal level and neighbourhood level) is associated with increased odds of smoking. Similar results were found by Shaw et $a l^{20}$, who showed that an increased experience of financial strain was associated with increased odds of both smoking and heavy drinking. Deprivation is not a synonym for income but is rather the consequence of income and many other determinants (eg, hardship, social exclusion). It seems plausible that the stress of personal deprivation, and perhaps, the contagion of neighbourhood deprivation (as deprived neighbourhoods in New Zealand have much higher smoking prevalence) cause people to start smoking-or make it less likely that they can stop.

Third, and as also shown previously in other studies, moving out of the family nucleus was also associated with increased odds of smoking in the present study. Sharing your life with a spouse or starting family life seems to have a positive impact on smoking behaviour ${ }^{1618}$ possibly due to concerns about secondhand smoking or experiencing the support of a partner when

Table 5 Summary of findings

\begin{tabular}{lll}
\hline & \multicolumn{2}{l}{ Change in smoking behaviour } \\
\cline { 2 - 3 } Change in social circumstance & Odds of smoking & $\begin{array}{l}\text { Number of } \\
\text { cigarettes } \\
\text { per day }\end{array}$ \\
\hline Decreasing personal income & $\begin{array}{l}\downarrow \downarrow \text { for } 15-24 \text { years }- \\
\text { for 25+ years }\end{array}$ & - \\
Increasing personal deprivation & $\uparrow$ & - or $\downarrow$ \\
Increasing neighbourhood deprivation & $\uparrow \uparrow$ & - \\
Moving out of a family nucleus & $\uparrow \uparrow$ & - \\
Moving from employment to 'inactive' & $\downarrow$ & $\downarrow$ \\
Moving from employment to unemployed & - or $\uparrow$ & - \\
\hline
\end{tabular}


trying to quit, whereas dissolution of family life seems to encourage smoking ${ }^{14}{ }^{15}$ possibly as a result of not experiencing such support mechanisms. Moving out of the active labour force, however, was associated with reduced odds of smoking and did not appear to be due to time-varying confounding by health status. Other studies have either found no association between employment trajectories and changes in smoking behaviour ${ }^{19}$ or associations between stable employment and trajectories from smoking to non-smoking. ${ }^{17}$

Regarding the number of cigarettes smoked per day, associations were largely null.

\section{Limitations}

The advantages of fixed effects analyses of panel data come at a cost; statistical power is usually much diminished as the power now arises from people changing on both the exposure of interest and the outcome of interest. CIs in our study are accordingly much wider than they would be for a cross-sectional (but hopelessly confounded) analysis of 15000 people. That said, our study was still powerful enough to detect associations (and many more than expected purely by chance) with CIs excluding the null.

Initial non-response and subsequent attrition (as is inevitable in a repeated measures study) means that about half of the initially intended population were still in the study by wave 7. Thus, selection bias, whereby the associations between variables observed among those remaining in the study are different from those not participating, is possible. However, we have shown elsewhere for the association of income with self-rated health that there appears to be no difference in the association among those leaving compared with those staying in the study. ${ }^{25}$

Residual time-varying confounding is possible. But if one tracks the associations of each covariate with the outcome across models 1-4 in tables 3 and 4, the strengths of association hardly alter with addition of more and more covariates (and potential time-varying confounders). Thus, if our findings were prone to time-varying confounding, it would have to be for a variable uncorrelated with those we have already adjusted for, and with strong (time varying) associations with both exposure and outcome. This seems unlikely.

\section{Policy implications}

Price elasticity of demand is the foundation stone for tobacco taxation. Our study finds a consistent income elasticity of demand for young people only. This adds further support to the view that price and income are particularly important for initiation among young people. As young people leave home and increase their income, the risk of starting smoking increases, pointing to the importance of policies that restrict supply and marketing that acts as a trigger for youth with new money in their pockets.

Supporting a social determinant of health paradigm, we find that increasing deprivation (personal or neighbourhood) is deleterious for the odds of smoking. More generally, simplistic expectations that improving social circumstances will always improve health are challenged by the findings in this paper (at least in the short run) and consistent with recent calls for more nuanced understandings of social determination and inequalities in health. ${ }^{26}$ Particularly relevant in this instance are time scale (eg, the acute effects of changes in financial circumstances may differ from the long-run impacts on smoking of greater affluence) and the modifying effects of age. Regarding changes in income, our study is consistent with increased odds of smoking among young people experiencing an increase in income. Over the long run, we would anticipate longstanding improvements in income are more health promoting, consistent with social determinants theory. Longer duration follow-up of repeated measures than we were able to achieve is warranted by researchers with access to such data.

\section{What this paper adds}

- Social position determines health status. But the causal associations of changes in social factors with change in smoking behaviour are not well researched or understood.

- This paper uses a panel study with repeated measures to examine changes in smoking with fixed effects regression.

- Worsening social circumstances over the short run are generally deleterious for smoking behaviour, but not always so. For example, decreasing personal income among young people was associated with decreased odds of smoking, consistent with income elasticity of demand (the less one's income, the less one can consume).

- This paper suggests that improving social determinants is not always pro-health over the short run; a more nuanced approach to the social determinants of health is required.

Acknowledgements Access to the data used in this study was provided by Statistics New Zealand in a secure environment designed to give effect to the confidentiality provisions of the Statistics Act, 1975.

Contributors TB initiated the study and obtained funding, and led the conception and design, interpretation and drafting of the paper. FSvdD undertook literature reviews and contributed to interpretation and drafting of the paper. IK and AW contributed to interpretation and drafting of the paper. KC co-leads the SoFIE-Health study, led the analyses and contributed to interpretation and drafting of the paper.

Funding The Health Research Council of New Zealand (grant number: 08/048).

\section{Competing interests None.}

Ethics approval Ethics approval was obtained for the SoFIE Health module from the University of Otago Ethics Committee, Wellington. The results in this study and any errors contained therein are those of the author, not Statistics New Zealand.

Provenance and peer review Not commissioned; externally peer reviewed.

Data sharing statement The SoFIE-Health data are available to bona fide researchers (upon application and approval) in the data laboratory at Statistics NZ. But the unit-level data are not available without Statistics NZ.

\section{REFERENCES}

1 Commission on Social Determinants of Health. Closing the gap in a generation: health equity through action on the social determinants of health. Geneva: The World Health Organization, 2008.

2 Hill S, Blakely T, Fawcett J, et al. Could mainstream anti-smoking programmes increase inequalities in tobacco use? New Zealand data from 1981-1996. Aust N Z J Public Health 2005;29:279-84.

3 Ministry of Health. A portrait of health: key results of the 2006/07 New Zealand health survey. Wellington: Ministry of Health, 2008.

4 Lawlor D, Frankel S, Shaw M, et al. Smoking and ill health: does lay epidemiology explain the failure of smoking cessation programs among deprived populations? Am J Public Health 2003;93:266-70.

5 Thomas S, Fayter D, Misso K, et al. Population tobacco control interventions and their effects on social inequalities in smoking: systematic review. Tob Control 2008; 17:230-7.

6 Kostova $D$, Ross $H$, Blecher $E$, et al. Is youth smoking responsive to cigarette prices? Evidence from low- and middle-income countries. Tob Control 2011;20:419-24.

7 Soteriades S, DiFranza J. Parent's socioeconomic status, adolescents' disposable income, and adolescents' smoking status in Massachusetts. Am J Public Health 2003;93:1155-60.

8 Scragg R, Laugesen M, Robinson E. Cigarette smoking, pocket money and socioeconomic status: results from a national survey of 4 th form students in 2000 . N Z Med J 2002;115:U108. 
9 Jensen R, Lleras-Muney A. Does staying in school (and not working) prevent teen smoking and drinking? J Health Econ 2012;31:644-57.

10 Grossman M. On the concept of health capital and the demand for health. J Polit Econ 1972;80:223-55.

11 Zandstra E, Miyapuram K, Tobler P. Understanding consumer decisions using behavioral economics. In: Pammi VSC, Srinivasan N, eds. Progress in brain research. Elsevier, 2013:197-211.

12 Allison PD. Fixed effects regression analysis for longitudinal data using SAS. Cary, North Carolina: SAS Institute Inc, 2005.

13 Gardiner J, Luo Z, Roman L. Fixed effects, random effects and GEE: What are the differences? Statist Med 2009;28:221-39.

14 Lee $\mathrm{S}$, Cho E, Grodstein F, et al. Effects of marital transitions on changes in dietary and other health behaviours in US women. Int J Epidemiol 2005;34:69-78.

15 Eng PM, Kawachi I, Fitzmaurice G, et al. Effects of marital transitions on changes in dietary and other health behaviours in US male health professionals. J Epidemiol Community Health 2005;59:56-62.

16 McDermott L, Dobson A, Owen N. Occasional tobacco use among young adult women: a longitudinal analysis of smoking transitions. Tob Control 2007;16:248-54

17 Giordano GN, Lindström M. The impact of social capital on changes in smoking behaviour: a longitudinal cohort study. Eur J Public Health 2011;21:347-54.
18 McDermott L, Dobson A, Owen N. Smoking reduction and cessation among young adult women: a 7-year prospective analysis. Nicotine Tob Rese 2008;10:1457-66.

19 Virtanen P, Vahtera J, Broms U, et al. Employment trajectory as determinant of change in health-related lifestyle: the prospective HeSSup study. Eur J Public Health 2008; 18:504-8

20 Shaw BA, Agahi N, Krause N. Are changes in financial strain associated with changes in alcohol use and smoking among older adults? J Stud Alcohol Drugs 2011:72:917-25

21 Carter KN, Cronin M, Blakely T, et al. Cohort profile: Survey of Families, Income and Employment (SoFIE) and Health Extension (SoFIE-health). Int J Epidemiol 2009;39:653-9

22 Salmond C, Crampton P, Atkinson J. NZDep2006 index of deprivation. Wellington: Department of Public Health, University of Otago, 2007.

23 Salmond C, Crampton P, King P, et al. NZiDep: a New Zealand index of socioeconomic deprivation for individuals. Soc Sci Med 2006;62:1474-85.

24 Edwards R, Peace J, Carter K, et al. An examination of smoking initiation rates by age: results from a large longitudinal study in New Zealand. Aust \& NZ J Public Health. In press.

25 Carter K, Imlach Gunasekara F, Mckenzie S, et al. Differential loss of participants does not necessarily cause selection bias. Aust N Z J Public Health 2012;36:218-22.

26 Mackenbach JP. The persistence of health inequalities in modern welfare states: the explanation of a paradox. Soc Sci Med 2012;75:761-9. 


\section{TC Do changes in income, deprivation, labour force status and family status influence smoking behaviour over the short run? Panel study of 15000 adults}

Tony Blakely, Frederieke S van der Deen, Alistair Woodward, et al.

Tob Control published online September 3, 2013

doi: 10.1136/tobaccocontrol-2012-050944

Updated information and services can be found at:

http://tobaccocontrol.bmj.com/content/early/2013/09/03/tobaccocontrol-2012-050944.full.html

\section{These include:}

References This article cites 19 articles, 7 of which can be accessed free at: http://tobaccocontrol.bmj.com/content/early/2013/09/03/tobaccocontrol-2012-050944.full.html\#re f-list-1

$\mathbf{P}<\mathbf{P} \quad$ Published online September 3, 2013 in advance of the print journal.

Email alerting service

Receive free email alerts when new articles cite this article. Sign up in the box at the top right corner of the online article.

Notes

Advance online articles have been peer reviewed, accepted for publication, edited and typeset, but have not not yet appeared in the paper journal. Advance online articles are citable and establish publication priority; they are indexed by PubMed from initial publication. Citations to Advance online articles must include the digital object identifier (DOIs) and date of initial publication.

To request permissions go to:

http://group.bmj.com/group/rights-licensing/permissions

To order reprints go to:

http://journals.bmj.com/cgi/reprintform

To subscribe to BMJ go to:

http://group.bmj.com/subscribe/ 